\title{
Research on Building Deformation Caused by the Excavation of Subway Station
}

\author{
Cuifeng Zuo ${ }^{1, a}$, Degao Tang ${ }^{1, b}$ and Dapeng $\mathrm{Li}^{2, \mathrm{c}}$ \\ ${ }^{1}$ College of Defense Engineering, PLA Univ of Sci and Tech, Nanjing, 210007, China; \\ ${ }^{2}$ No.5 Air Defense Engineering Department of PLA Air Force, Nanjing, 210007, China \\ awindyzuo1991@163.com, 'bang1962@163.com, 'dapengdp@126.com
}

\begin{abstract}
Keywords: field observation; subway station; nearby buildings; ground surface settlement; deformation characteristic

Abstract. A database of 30 deep excavations of field monitoring on Nanjing subway stations is presented and discussed. In order to reflect the differences of settlement in different area around the excavation, monitoring points were arranged at three areas: (1) the position $1 / 4$ and $1 / 2$ long side, or the long side of excavation for short; (2)the width direction of excavation and the section within the range of 1/10 long side, or the short side of excavation for short; (3)area of soil arching root. Research indicates that: The final pattern of ground surface settlement is groove shape. The deformation of excavation appears obvious three-dimensional characteristic. According to the subarea of ground surface settlement proposed and the relative location between the building and excavation, the deformation type and leaning direction of nearby building can be quickly predicted. These conclusions will be contributed to the future construction of subway stations, and can give effective protection to the buildings around the deep excavation.
\end{abstract}

\section{Introduction}

At present, subway construction comes into a climax because of the requirement of infrastructures in many cities in China. Subway engineering includes a large number of stations which are always located downtown, and in which deep excavation are usually executed; therefore nearby buildings are inevitably influenced by the construction. Correspondingly, the protection of surrounding building becomes more and more important. Without paying attention to this issue, it may lead to engineering accidents such as building distortion, third party impact, and even loss of invaluable historic property [1]. For example, during the construction of a certain station in Nanjing subway $2^{\text {nd }}$ line, with a depth of $17.5 \mathrm{~m}$, a building $16 \mathrm{~m}$ away from the excavation firstly subsided westward, and then it became a dangerous structure with a lean of over $0.8 \%$. At the same time, 2 fifty-floor residential buildings emerged numerous fissures which extended from the roof. This accident not only induced enormous economic losses, but also seriously interfered with normal life of the residents, causing abominable social influence in Nanjing [2]. For preventing damage to the nearby buildings, it is necessary to grasp the deformation characteristic of building around the deep excavation [3-5].

The deformation caused by deep excavation presents conspicuous three-dimensional characteristics [6-8], however, for simplicity, the excavation was usually considered as a plane strain problem in previous studies. The deformation of building adjacent to excavation was also discussed based on the principle mentioned above $[9,10]$. For deep excavation, plane strain pattern can be used in the central strip of the long side, while it isn't available for the short side and the edge of the long side where the deformation is quite different from that pattern. The building located around the excavation corner also displays complicated three-dimensional deformation characteristic, but seldom studied.

Through monitoring data of Nanjing subway $3^{\text {rd }}$ line, $10^{\text {th }}$ line and Ning-Tian intercity railway, the pattern of ground surface settlement in different areas around the deep excavation is studied, thereafter deformation of surrounding buildings is analyzed in this paper. The research result 
facilitates a more thorough understanding of deformation characteristic, and what is more, it can provide valuable reference for the protection to buildings around the excavation.

\section{Engineering backgrounds}

The distinguishing features of open-cut method such as its good working environment; safe and fast; and economic, make it become the widely used method of underground subway station construction. There are 55 stations in Nanjing subway $3^{\text {rd }}$ line, $10^{\text {th }}$ line and Ning-Tian intercity railway in total, 43 of them are underground stations. 30 underground station deep excavations, representing typical Nanjing area geology condition, are selected for field observation. The analysed samples occupy $55.8 \%$ of the summation. The physico-mechanical parameters of soils around the selected station excavations are displayed in Table 1.

Table 1 Physico-mechanical parameters of soils

\begin{tabular}{ccccccc}
\hline Name & $\begin{array}{c}w / \\
{[\%]}\end{array}$ & $\begin{array}{c}\gamma / \\
{\left[\mathrm{kN} \cdot \mathrm{m}^{-3}\right]}\end{array}$ & $\begin{array}{c}c / \\
{[\mathrm{kPa}]}\end{array}$ & $\begin{array}{c}\varphi / \\
{\left[{ }^{\circ}\right]}\end{array}$ & $\mu$ & $\begin{array}{c}E_{s I-2} / \\
{[\mathrm{MPa}]}\end{array}$ \\
\hline Miscellaneous fill & - & - & - & - & - & - \\
Plain fill & 25.0 & 19.0 & 10 & 15.0 & 0.382 & 5.41 \\
Silty clay & 26.1 & 19.3 & 36 & 23.3 & 0.349 & 6.34 \\
Silty clay & 25.5 & 19.5 & 32 & 22.1 & 0.342 & 6.82 \\
Silty clay & 23.2 & 19.9 & 20 & 19.6 & 0.338 & 9.93 \\
Residual soil & 21.2 & 20.0 & 23 & 28.0 & 0.312 & 8.54 \\
Decomposed rock & - & 23.7 & 35 & 30.5 & 0.269 & 35.2 \\
\hline
\end{tabular}

The supporting structures for the 30 excavations are diaphragm wall with $800 \mathrm{~mm}$ in thickness or bored concrete piles together with braces. The shapes of the selected excavations are all rectangular. The distribution of the corresponding depth, width and length are illustrated in Fig. 1(a), (b) and (c) respectively.

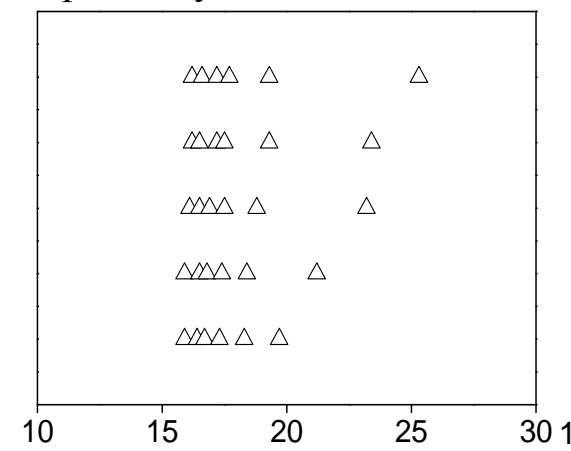

(a) Depth (m)

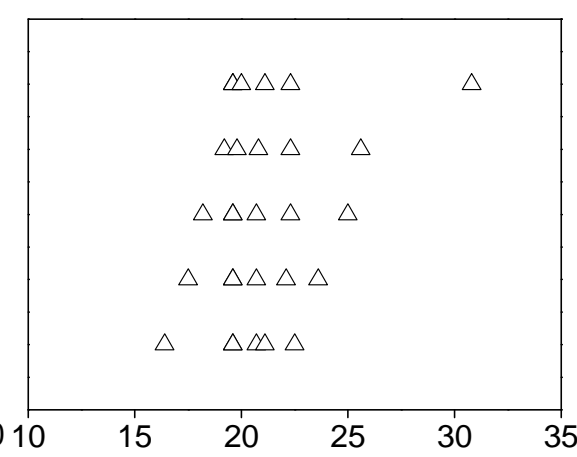

(b) Width (m)

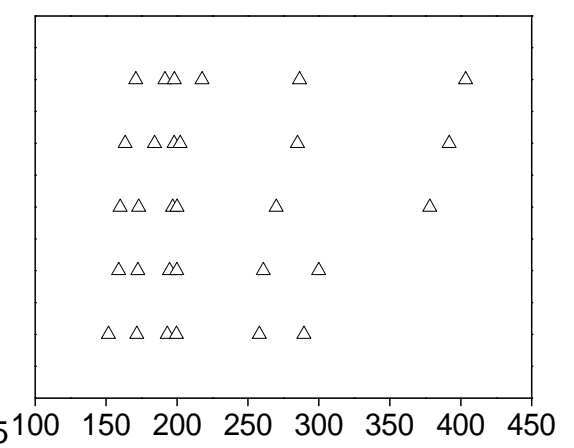

(c) Length (m)

Fig.1 Distributions of excavation depth, width and length

\section{Ground surface settlement caused by deep excavation}

30 subway station deep excavations, representing typical Nanjing area geology condition, are selected for field observation. As illustrated in Fig.2, in order to reflect the differences of settlement in different area around the excavation, monitoring points were arranged at three areas: (1)the position 1/4 and 1/2 long side (the long side of excavation for short); (2)the width direction of excavation and the section within the range of 1/10 long side (the short side of excavation for short); (3)area of soil arching root. Note that, the width and 1/10 length of the deep excavation is almost the same as excavation depth, thus the pertinent areas are obviously influenced by spatial effect. Due to soil arching effect caused by the lateral displacement of the support, the area of soil arching root is actually stress-intensive regions where the settlements are also different from other areas. The monitoring points are arranged at various distances from the excavation, so as to observe the ground surface settlement characteristics. 


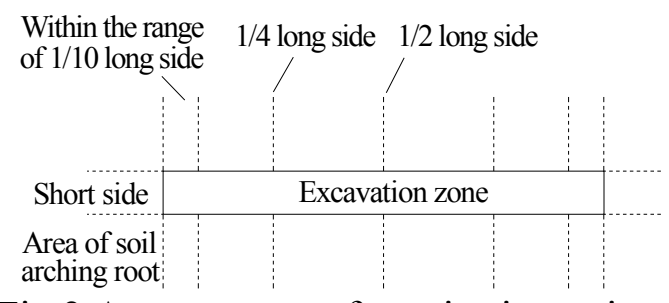

Fig.2 Arrangement of monitoring points

The final ground surface settlement distribution is derived through 450 monitoring points (Fig.3), which were arranged at three areas around deep excavation.

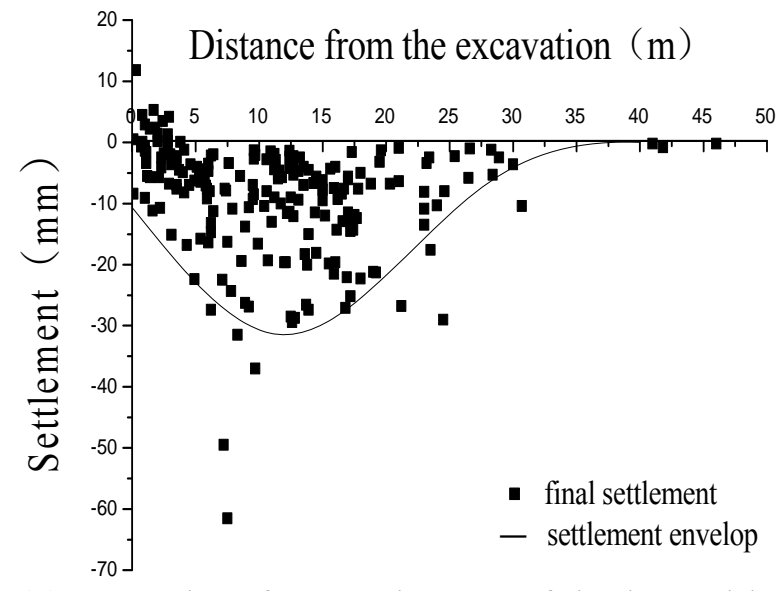

(a) Ground surface settlement of the long side

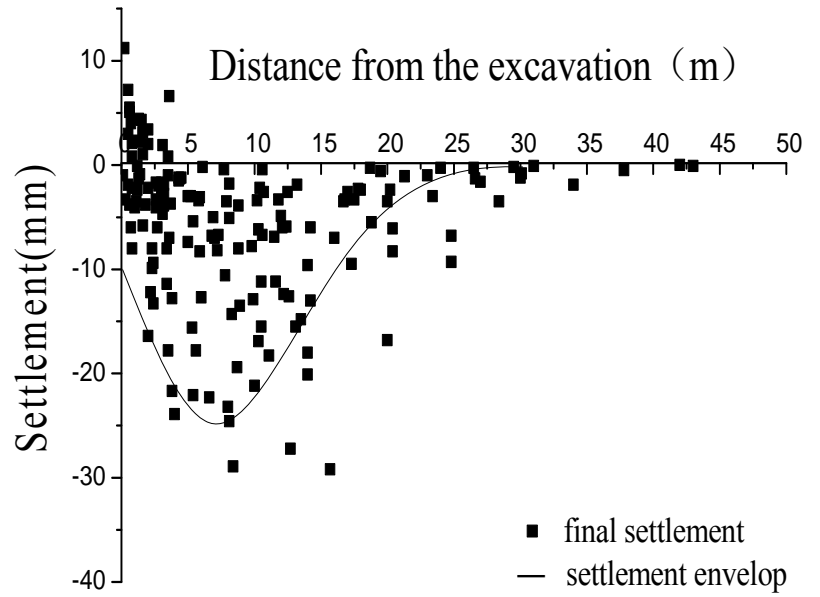

(b)Ground surface settlement of the short side

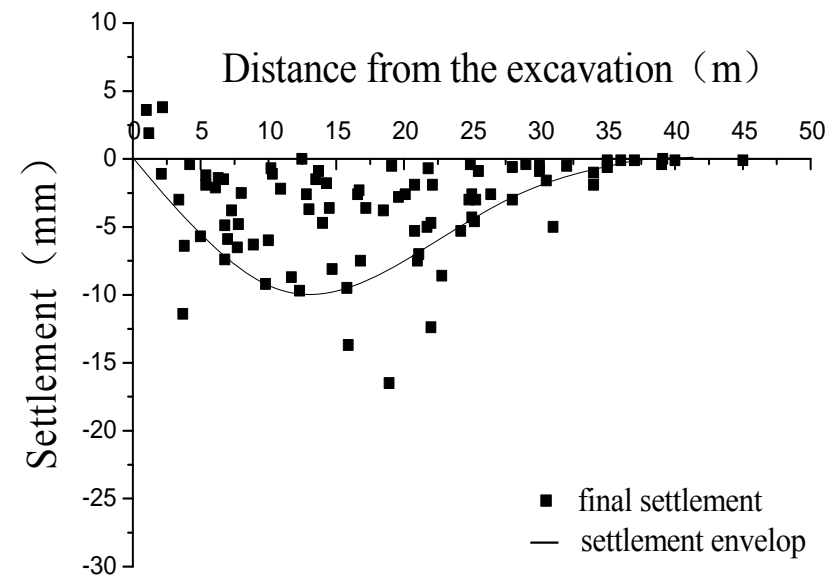

(c) Ground surface settlement of area of soil arching root

Fig. 3 Ground surface settlement of different areas

According to the envelopes as shown in Fig.3(a)-(c), the final patterns of ground surface settlement are all groove shape in different areas, however, there are differences among the maximum ground surface settlement, maximum ground surface settlement position, inverse ground surface settlement position and the influential range. The results verify the spatial effect of the deep excavation. For simplicity, as Fig.4 displays, "broken line shape" is substituted for groove shape. "maximum settlement line", "inverse settlement line", "settlement boundary" in Fig.4 can be generally called "the key lines of the settlement". According to Fig. 4, the vertical view of the subarea of ground surface settlement can be gained (Fig.5).

Fig. 5 indicates that the ground surface around the excavation can be divided into four areas, namely areas A, B, C and area D, where area A is in plane strain condition, and areas B, C, D are influenced by spatial effect. The key lines of settlement (solid line) in areas A, C, D can be regarded as the contours of the settlement, while the transitional dotted lines in each area and solid line in area $\mathrm{B}$ are not the ones. Owing to bilateral asymmetry, the characteristic line of the central strip in area B 
isn't the contours of settlement. Based on the key lines of settlement in Fig.5, the deformation characteristic of nearby buildings can be predicted quickly. The law of deformation is described below in detail.

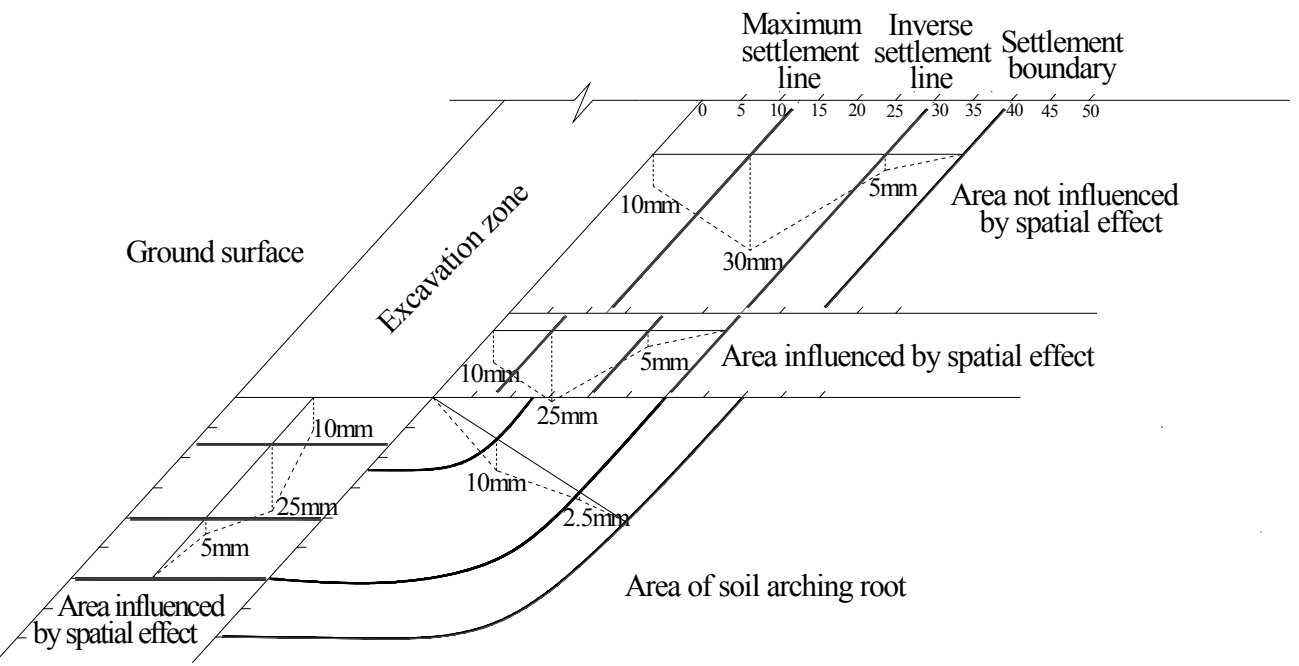

Fig.4 Final patterns of ground surface settlement

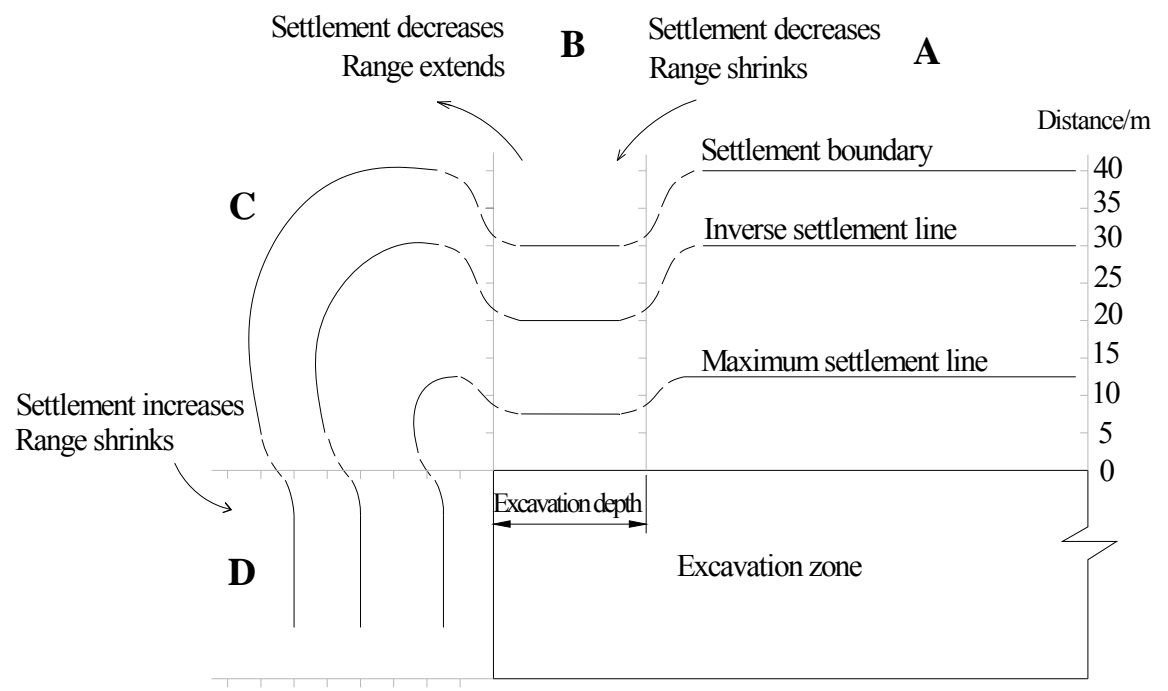

Fig.5 Vertical view of the subarea of ground surface settlement

\section{The deformation characteristic of surrounding building}

\section{Building in area $\mathbf{A}$ is perpendicular or parallel to the excavation}

The essence of deformation of adjacent building is the differential settlement caused by excavation. For discussion purposes, building in the length direction will be referred to as the longitudinal wall and that in width direction as transverse wall. As shown in Fig. 6, when the longitudinal wall of the building in area A is parallel to the excavation, deflection deformation occurs in the transverse wall, but that would not occur in the longitudinal walls because of uniform settlement. When the longitudinal wall of the building is perpendicular to the excavation, the conclusion is contrary. 


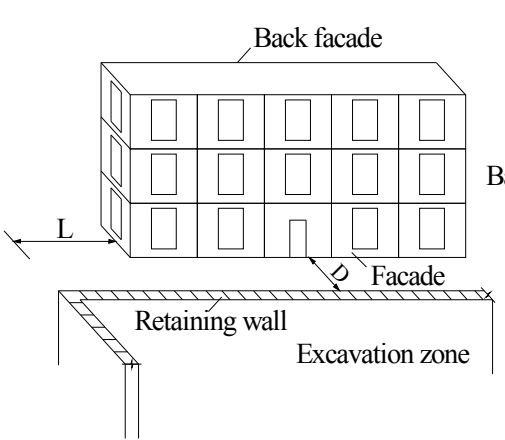

(a)Parallel

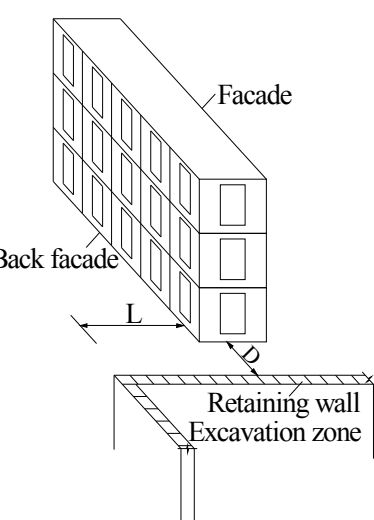

(b) Perpendicular

Fig.6 Relative position between building and the excavation

As shown in Fig.7, with the increase of distance between the building and the excavation, "sagging deformation" occurs when the building passes through the maximum settlement point. In the meantime, the tensile strain of the wall is in a state of " $\backslash /$ ", when that reaches the critical value, fissures which look like " $\backslash$ "will emerge at the two sides of the lowest point of settlement trough. On the contrary, when the building passes through the inverse settlement position, "hogging deformation" occurs and the tensile strain is in the state of "/ $\mid$ ". Fissures which look like " $/$ " will emerge when the tensile strain reaches critical state. The conclusions show close agreement with the results of numerical simulation of Zheng Gang [11].

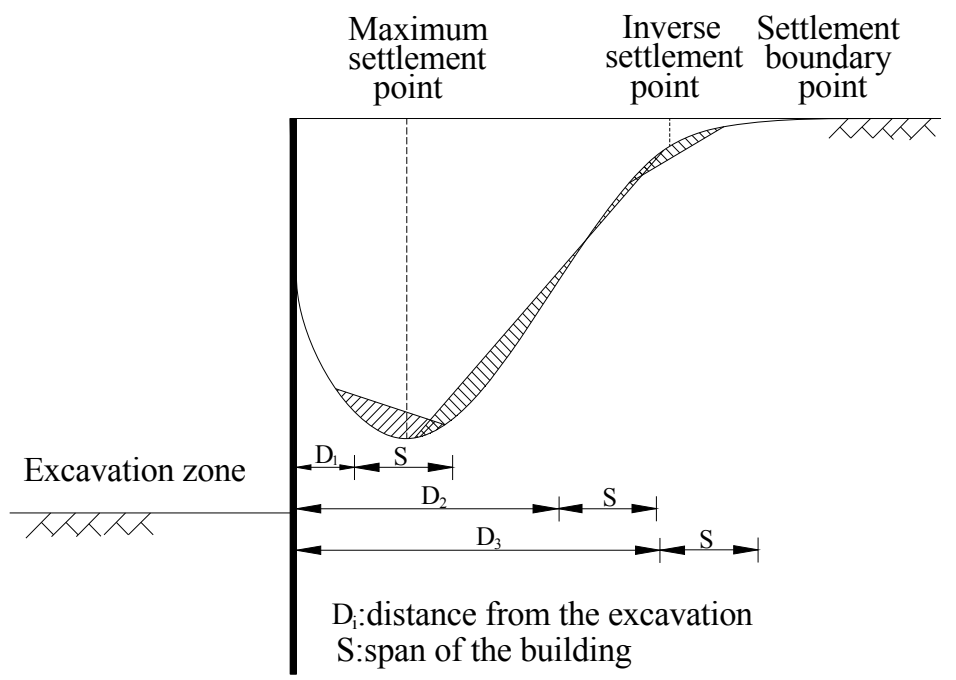

Fig.7 Deflection deformation of building

\section{Building in area $A$ with arbitrary angle adjacent to excavation}

When the building isn't perpendicular to the excavation as illustrated in Fig. 8, both the longitudinal wall and transverse wall are influenced by differential settlement. Thus, for building, not only the deflection deformation but also the torsion deformation occurs. 


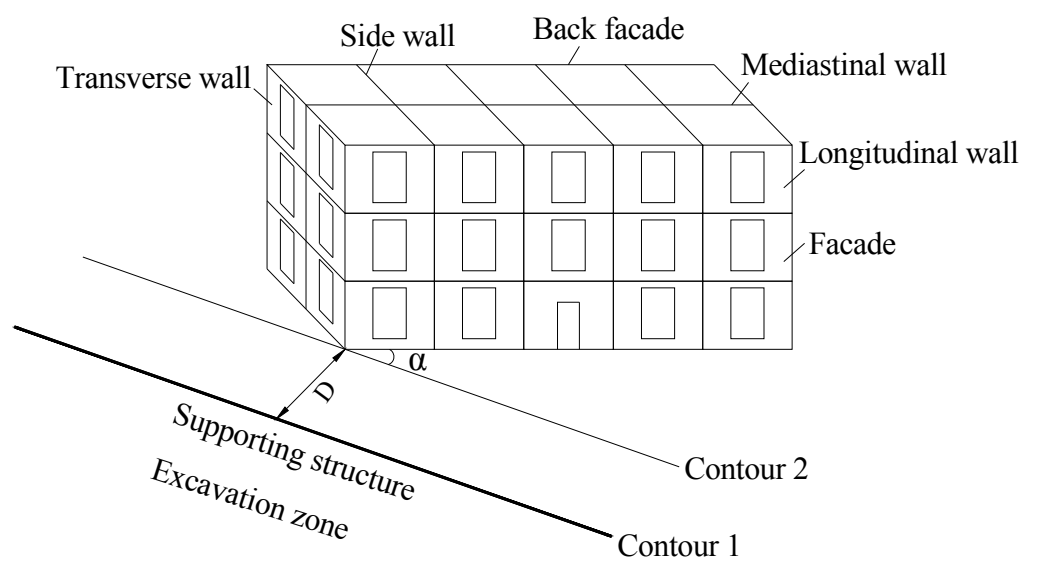

Fig.8 Building with arbitrary angle adjacent to excavation

For torsion deformation of building, one of the most important aspects is the torsional direction. According to Fig. 9, when the building passes through the lowest point, the whole building is affected by sagging deflection deformation. At the same time, in terms of the longitudinal wall, the maximum settlement position of the back facade is closer to the facade of the transverse wall than that of the facade; then torsion deformation occurs, where the torsional direction of facade is clockwise, and that of back facade is counterclockwise. For the facade of transverse wall, the left angular point is closer to the maximum settlement point than the right one, so the torsional direction is counterclockwise. Similarly, the torsional direction of the back facade of transverse wall can also be achieved based on the analysis of the situation of angular points, and the result is clockwise. Note that, clockwise, counterclockwise, left, right mentioned in this article is determined by the relative position between the observed object and the observer who always faces the facade.

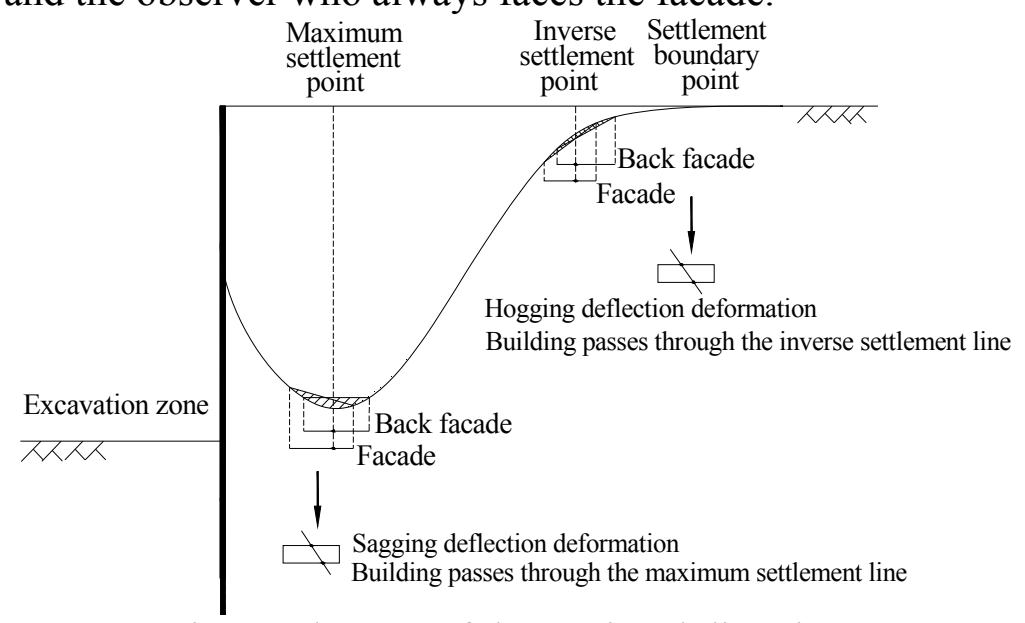

Fig.9 Judgment of the torsional direction

When the building passes through the inverse settlement point, the pertinent deformation characteristic and torsional direction can be studied in the same way as stated above. In Table 2, the judgment of the torsional direction of building is summarized.

Table2. The judgment of the torsional direction of the building

\begin{tabular}{cccc}
\hline Wall type & Elevation & $\begin{array}{c}\text { Building passes through the } \\
\text { lowest point }\end{array}$ & $\begin{array}{c}\text { Building passes through the } \\
\text { inverse point }\end{array}$ \\
\hline \multirow{2}{*}{ Longitudinal wall } & Facade & Clockwise & Counterclockwise \\
& Back facade & Counterclockwise & Clockwise \\
Transverse wall & Facade & Counterclockwise & Clockwise \\
& Back facade & Clockwise & Counterclockwise \\
\hline
\end{tabular}

Note: The direction determined by the observer who always faces the facade. 


\section{Building located in the corner----the building is parallel to the excavation}

The excavation leads to both deflection deformation and torsion deformation of the building, which located around the corner. As Fig. 9 shows, five representative buildings are displayed to analyze the deformation characteristics of the building situated around the corner herein.

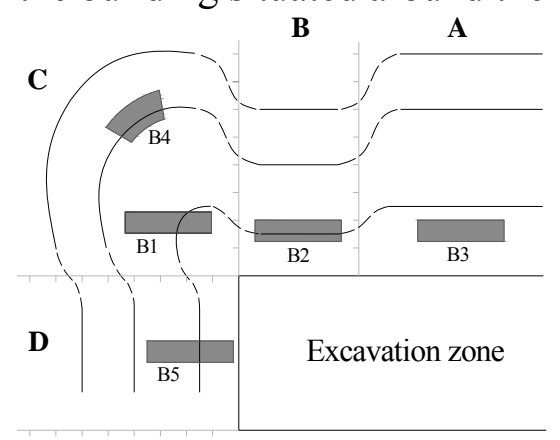

Fig. 10 The building is parallel to the excavation corner

In terms of building 1(B1 for short in Fig. 10, as follows), the transverse wall isn't parallel to the maximum settlement line, so torsion deformation occur between the two longitudinal walls, the same deformation appears in the transverse wall afterwards. The longitudinal wall near the excavation rotates counterclockwise, and that far away from excavation rotates clockwise. The transverse wall near the excavation rotates clockwise, and that far away from excavation rotates counterclockwise (the observer stand by the excavation).

As mentioned above, the characteristic line in area B isn't the contour of settlement result from bilateral asymmetry. Thus there is torsion deformation between the two transverse walls of building 2 , thereafter torsion occurs on longitudinal wall. The torsional direction can be judged correspondingly.

The settlement increases obviously from area $\mathrm{C}$ to area $\mathrm{B}$, and it will give rise to increasing deflection deformation of the longitudinal wall from building 1 to building 2 . Then, the deflection deformation decreases gradually, as the settlement of the longitudinal wall tends to uniform. When the location reaches to building 3 , as we have known, the building 3 is in plane strain condition, so the settlement of the longitudinal wall is uniform, and deflection deformation only occurs in the transverse wall.

For curved building 4 in area $\mathrm{C}$, it is deflection deformation rather than torsion deformation that occurs, because the curved longitudinal wall is parallel to the contour of settlement.

Referring to next part, the deformation characteristic of building 5 can be gained.

\section{Building located in the corner----the building is perpendicular to the excavation}

As Fig. 11 displays, building 1 passes through the maximum settlement line, and its transverse wall isn't parallel to that line, hence torsion deformation occurs on the longitudinal wall. In addition, deflection deformation also appears on the longitudinal wall. The deformation characteristic of building 2 is similar to building 1 . For building 3 , it is in plane strain condition, so only deflection deformation appears.

The building 4 passes through the inverse settlement line, therefore the hogging deformation and torsion deformation appears. The specific deformation characteristic can be obtained through the relative position between the building and the inverse settlement line.

For buildings with arbitrary angle adjacent to the corner, such as building 6, similarly, the deflection deformation and torsion deformation can also be achieved according to the relative position between the building and the key line of settlement.

The deformation characteristic of building 5 can refer to the part of "Building located in the corner----the building is parallel to the excavation". 


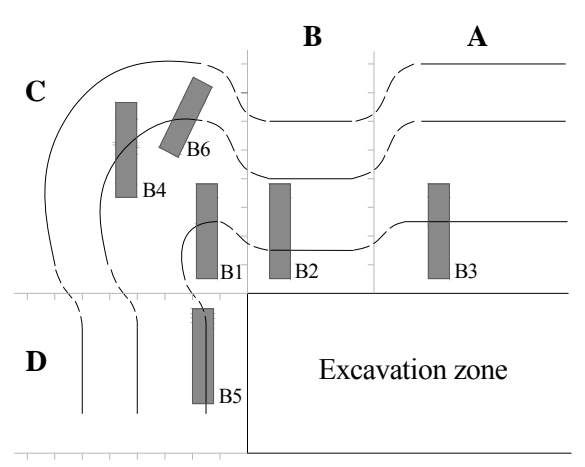

Fig. 11 The building is perpendicular to the excavation

\section{The leaning direction of building in different position around the corner}

With differential settlement, relative deformation among parts of the building is torsion deformation and deflection deformation, while relative displacement between the whole building and ground presents "incline". The research of the dip direction has vast importance to the protection to the building adjacent to the corner.

Zheng Gang's study [12] indicates that: The contour of settlement is parallel to the excavation invariably regardless of the angle between the building and the excavation. Therefore, the leaning direction is perpendicular to the contour of settlement, in other words, that is along the ground settlement gradient. And the leaning direction has nothing to with the angle between the building and the excavation.

(1) The key line of settlement in solid line is the contour of settlement in areas A, C, and area D, so the dip direction is perpendicular to the key line.

(2)In the transition stage from area C to area B, the key line of settlement (dotted line) isn't the contour of settlement. Actually, the settlement increases obviously. Therefore, the direction of ground settlement gradient is shown in Fig. 12, namely the building slants to the excavation, and that is just the leaning direction of the whole building.

(3)In area B, the key line of settlement (solid line) isn't the contour of settlement either, and the value of settlement increases in the same settlement line. Therefore, the building tilts towards the excavation.

(4) The key line of settlement expands in the transition stage from area B to area A. The value of settlement in the same key line gradually tends to stable extreme, i.e. the key line in area B becomes the contour of settlement in area A gradually, so the leaning direction tends to be perpendicular to the key line of settlement until that is totally perpendicular to the key line in area A.

(5) In the transition stage from area $C$ to area $D$, due to the obvious increase of settlement, the building slants to the excavation, as show in Fig. 12. This situation is the same as the situation (2).

(6)When the building located outside of the maximum settlement line, it slants to the excavation, namely the direction of thick solid arrow (Fig. 12); when the building close to the excavation, that is to say, the building located between the maximum settlement position and the excavation, it deviates from the excavation, namely the direction of the thin solid arrow as shown in Fig. 12.The building slants slight due to smaller settlement. In the zone from area $\mathrm{C}$ to area $\mathrm{B}$, and from area $\mathrm{C}$ to area $\mathrm{D}$, the settlement increases obviously, thus the building generally tends to slant to the excavation instead of deviating.

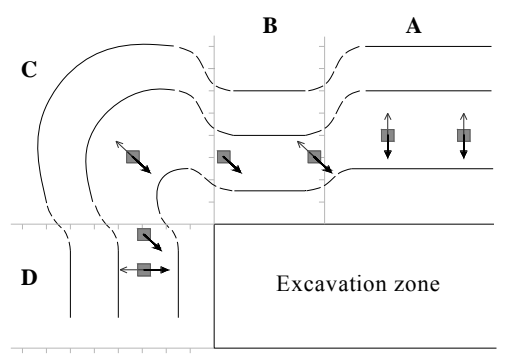

Fig.12 The direction of dip of building in different position around the corner 


\section{Conclusions}

A database of some 30 case histories of ground surface settlements due to deep excavation in Nanjing is presented. The ground surface settlements and the deformation characteristic of surrounding building are studied extensively. The main conclusions are described in the following:

(1)The settlement of different position around the corner is quite different. When the position of long side is far away from the corner, then the long side can be considered to be in plane strain condition.

(2)With the difference of relative position between the building and the excavation, the deflection deformation or the torsion deformation occurs correspondingly. The building deformation type can be predicated quickly based on the subarea of ground surface settlement.

(3)The leaning direction of building adjacent to the excavation corner is closely related to its position.

The results can provide references for the construction of deep excavation, and can give effective protection to the building around the excavation.

\section{References}

[1] S. Moorak and J. C. Edward: Journal of Geotechnical and Geoenvironmental Engineering, 131, 162-177(2005).

[2] G.B. Liu and W. D. Wang: Excavation Engineering Manual (second edition)(China Architecture and Building press, Beijing, in Chinese 2009).

[3] R. Grant, J.T. Christian and E.H. Vanmarcke: Journal of the Geotechnical Division, 100(9), 973-991(1974).

[4] M.D.Boscardin and E. J. Cording: Journal of Geotechnical and Geoenvironmental Engineering, 115(1), 1-21(1989).

[5] M. Son and E. J. Cording: Journal of Geotechnical and Geoenvironmental Engineering, 131(2), 162-177(2005).

[6] C.Y. Ou, B.Y. Shiau and I.W. Wang: Canadian Geotechnical Journal, 37(2), 438-448 (2000).

[7] G. Zheng and Zh.W. Li: Journal of Tianjin University, 45(8):688-699. (in Chinese 2012 )

[8] J.Y. Li and Z.X. Zhang: Chinese Journal of Underground Space and Engineering, 8(1), 71-77(in Chinese 2012).

[9] X.W. Liu, Z.Y. Shi, D.Q. Yi and S.M. Wu: Chinese Journal of Geotechnical Engineering, 21

(4), 456-460(in Chinese 1999).

[10] Z.H. Xu, J.H. Wang and W.D. Wang: China Civil Engineering Journal, 41(8), 81-86(in Chinese 2008).

[11] G. Zheng and Zh.W. Li: Chinese Journal of Geotechnical Engineering, 34(4):615-624(in Chinese 2012).

[12] G. Zheng and Zh.W. Li: Chinese Journal of Geotechnical Engineering, 34(6):969-977(in Chinese 2012). 